\title{
NEWS
}

\section{Big science feels the pinch in Europe}

\section{Financial hard times in member states are fuelling calls for budget savings across the board.}

Long insulated by multi-year budgets and treaties, Europe's multinational research organizations and the glittering scientific projects they fund are finally feeling the financial pain of their member states. This week, representatives from the 20 nations involved in CERN, Europe's particle-physics laboratory near Geneva, Switzerland, meet to discuss budget cuts for the laboratory over the next five years. In the next few months, Nature has learned, other organizations are facing decisions on whether to delay new projects, put upgrades on hold or make cuts in an attempt to appease their struggling member states.

"We are all very worried about the financial situation," says Francesco Sette, director of the European Synchrotron Radiation Facility (ESRF) in Grenoble, France.

For decades, the nations of Europe have built impressive scientific facilities through cooperation. Money from across the continent has gone to construct the Large Hadron Collider (LHC), the world's most powerful particle accelerator, which is located at CERN. Similar efforts have created the world-class European Molecular Biology Laboratory (EMBL) in Heidelberg, Germany, a series of massive telescopes in the Chilean desert and spacecraft to observe Earth and beyond.

\section{Extraordinary measures}

In the European fashion, financing for these projects is agreed through painstaking, multilateral negotiations. Most organizations are overseen by independent councils composed of scientists and bureaucrats from the member governments. Budget negotiations can be long, but usually result in stable funding that stretches years into the future (see 'Steady as they go?'). The organizations operate under treaties that ensure committed funding is rarely pulled, providing an extra level of security.

At CERN, the budget process often generates debate. But as the organization planned its latest five-year budget this spring, it met unusually strong resistance from member states, notably the United Kingdom. As a result, the CERN council rejected the five-year budget and asked the laboratory to come up with a plan to save money. The new strategy will be discussed at an extraordinary meeting of the organization's financial council on 25 August and includes plans to suspend activities at CERN's smaller accelerators during a 2012 shutdown of the LHC, delay renovating the

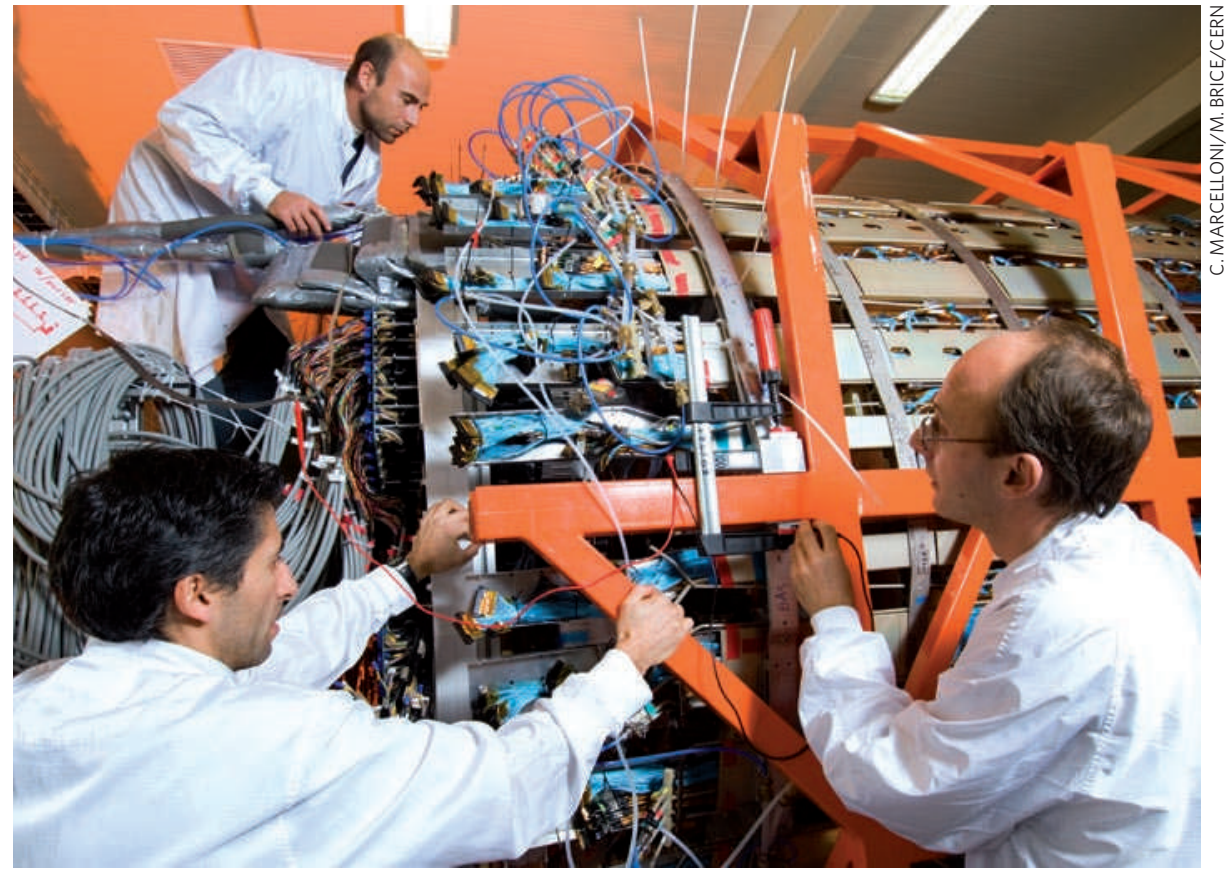

Researchers at CERN have been asked to hunt high and low for budget cuts.

lab's ageing buildings, and slow down development of the Compact Linear Collider advanced accelerator technology.

"CERN is in some sense a bellwether," says John Womersley, director of science programmes at the UK Science and Technology Facilities Council, which oversees many of Britain's subscriptions to international research bodies. Britain's newly elected coalition

\section{STEADY AS THEY GO?}

Europe's science organizations have long received stable funding but now face a more uncertain future.

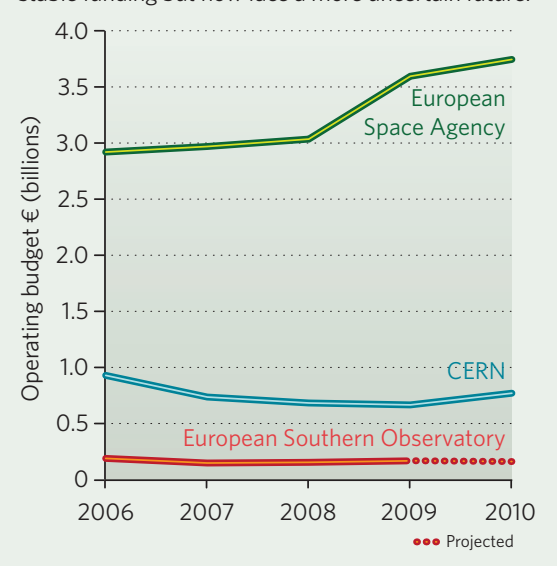

government is planning deep cuts in public spending to cope with a growing budget deficit, and Womersley says that his council is facing a difficult choice: fund projects abroad or support scientists at home. In the coming months, as more of Europe's treaty organizations bring budgets up for review, Womersley says that Britain will be calling for tough savings across the board.

The United Kingdom is usually the thirdlargest contributor to cooperative efforts, behind France and Germany, and its hard line is creating difficulties. At the synchrotron facility in Grenoble, Sette says that the British delegation to the governing council has asked it to outline the consequences of three scenarios: a flat budget, a $10 \%$ cut and a budget for minimal operations. The timing couldn't be worse for the ESRF, which is just embarking on a sevenyear, $€ 100$-million (US\$127-million) upgrade to its facilities. "We are today at a very critical stage," he says. "A major cut would imply a complete rethinking of the medium- and longterm strategy for the lab."

Britain is not the only European state with financial difficulties. Italy and Spain, among others, are also facing domestic budget crises that are causing trouble. Iain Mattaj, director of the EMBL, says that several countries 
unexpectedly announced in June that they might have trouble paying their dues in the coming year. Mattaj declined to name which nations were struggling.

"The situation is not easy for anyone," says Franco Bonacina, a spokesperson for the European Space Agency in Paris. As a result of the downturn, the agency has decided to put its plans for new missions largely on hold. Fresh projects are normally agreed during triennial meetings of research ministers, but there will be no meeting in 2011. Instead, the agency hopes that a lower-key delegation can approve two critical starts - an extension to the International Space Station programme until 2020, and funding to develop the next generation of the Ariane 5 rocket.

\section{A stimulating solution}

Not all plans for the future are on hold, however. Budget cuts have "never been something that's been asked of us," says Colin Carlile, director of the European Spallation Source, a new neutron-scattering facility to be located in Lund, Sweden. Carlile says that the Scandinavian member We states who origi"We are all very nally backed the worried about Lund site have so far the financial remained commitsituation." ted, as have other partners, including Spain. At present, the $€ 1.5$-billion facility is still on track to begin construction in 2013, he says, noting that the distant start date has insulated his group somewhat from the current financial problems.

Tim de Zeeuw, director-general of the European Southern Observatory, headquartered in Garching, Germany, says that in the next financial year he plans to ask for funds to start developing the European Extremely Large Telescope, a 42-metre-diameter behemoth. De Zeeuw points out that much of the telescope's $€ 1$-billion budget will go to hightech companies in Europe, which will design its optics and instrumentation. "If we want to stimulate our economy, this is a fine way of doing it," he says.

Womersley says that Britain hopes to participate in the new telescope, although the fiscal realities the country now faces may prove to be an obstacle. More generally, he hopes that Europe's patchwork of international partnerships will be able to negotiate the crisis. "We certainly don't want to see long-term damage to the future prospects of these organizations," he says.

Geoff Brumfiel

\section{Sugar synthesis speeds up}

Robot sub probes

Deepwater Horizon's underwater impact.

go.nature.com/6Q1gVR

\section{BOSTON, MASSACHUSETTS}

When biologists need a particular peptide or strand of DNA, they ask a machine to make it for them. Automation gives fast, inexpensive access to these molecules, and it has helped turbocharge biology.

But constructing complex carbohydrates from sugar building blocks still needs expert chemists, with researchers spending weeks - and tens of thousands of dollars forging molecules by hand.

Two groups of chemists now say they have independently developed automated carbohydrate synthesizers with the aim of making the molecules on demand. One machine is already churning out carbohydrates for clients, and the other will be available for labs to buy next year. Advocates say the machines could unplug a major bottleneck in the field of glycobiology, which studies the sugar chains (glycans) present on many proteins and lipids.

The main problem with carbohydrate synthesis is that sugar building blocks attach to each other in myriad ways to create a dazzling variety of branched structures — in contrast to peptides, which are made from a linear chain of amino acids linked by identical chemical bonds. Making the right carbohydrate means avoiding all the unwanted possibilities. great to manufacture. So Seeberger has spent the past decade completely remodelling his machine - overhauling the chemistry that links the sugars to the resin, for example.

Commercial machines will be available next year, he says. The device is being tested at Leiden University in the Netherlands and the University of Alberta in Edmonton, Canada. It is also being used by Ancora Pharmaceuticals, based in Medford, Massachusetts, a company co-founded by Seeberger to design and test carbohydratebased vaccines. Seeberger says that $90 \%$ of known mammalian carbohydrates can be constructed using just 35 building blocks, which he plans to supply in bulk.

Seeberger presented the early fruits of research using his machines at this week's American Chemical Society meeting in Boston, Massachusetts. For example, he is imaging sugar-covered bacterial cells - and targeting drugs at them - by attaching a variety of glycans to nanoparticles.

Not everyone thinks Seeberger's technology is currently versatile enough to make a wide range of carbohydrates on demand. "I don't think the chemistry is sufficiently well developed," says GeertJan Boons at the University of Georgia in Athens. But it could build libraries of carbohydrates using well-established
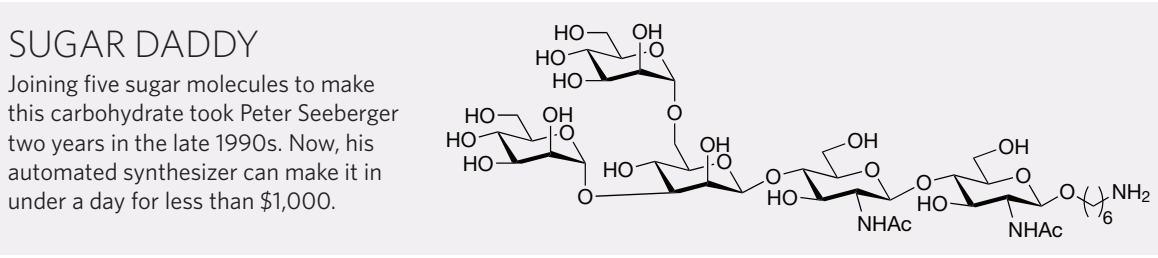

In 2001, chemist Peter Seeberger, who now directs the Max Planck Institute of Colloids and Interfaces in Potsdam, Germany, published the outline of a carbohydrate synthesizer that attached sugars one by one to a resin-linked chain (O. J. Plante, E. R. Palmacci and P. H. Seeberger Science 291, 1523-1527; 2001). The idea was based on solid-phase peptide synthesis, which won biochemist Bruce Merrifield the Nobel Prize in Chemistry in 1984; the resin holds on to the growing peptide or carbohydrate chain, with unreacted building blocks being washed away. But many researchers believed the chemistry behind Seeberger's proposal would be too complicated to be reliable, and the number of different sugars needed too synthetic routes, he adds.

Meanwhile, a complementary system is already delivering shorter carbohydrates than those targeted by Seeberger. Developed by Nicola Pohl of Iowa State University in Ames, it uses a hydrophobic fluorocarbon tag, rather than a resin, to anchor growing sugar chains in solution. Pohl's company, LuCella Biosciences in Ames, has been filling orders to build carbohydrates since November 2009. Pohl hopes that automated machines will persuade more biologists to study glycans rather than being deterred by their complexity. "A lot of our early work is about educating the biologists that these carbohydrates are now readily available," she says.

Richard Van Noorden 